\title{
The genetics of New World monkey visual pigments
}

\author{
Daniela Maria Oliveira Bonci ${ }^{1}$, Maureen Neitz ${ }^{2}$, Jay Neitz ${ }^{2}$, Luiz Carlos de Lima Silveira ${ }^{3}$, and \\ Dora Fix Ventura ${ }^{1}$ \\ 1- Universidade de São Paulo, São Paulo, SP, Brazil \\ 2- University of Washington, Seattle, WA, USA \\ 3- Universidade Federal do Pará, Belém, PA, Brazil
}

\begin{abstract}
To have color vision, having at least two cone photopigment types with different spectral sensitivities present in distinct photoreceptors is necessary together with the neural circuitry necessary to extract color information. Visual pigments are highly conserved molecules, but differences can be found among vertebrate groups. Primates have a variety of cone photopigments (i.e., opsins) that are expressed by polymorphic genes. This article examines the diversity of cone photopigments in New World monkeys and their behavioral relevance. Keywords: primate, color vision, opsin, cones, molecular genetics.
\end{abstract}

Received 13 September 2012; received in revised form 12 June 2013; accepted 13 June 2013. Available online 18 November 2013.

\section{Introduction}

During evolution, selective pressures for color vision gave rise to different color vision capacities across vertebrate groups. For example, reptiles and birds discriminate a larger number of chromatic stimuli compared with mammals (Hart \& Hunt, 2007; Zana, Ventura, de Souza, \& DeVoe, 2001). During the Paleozoic Era, mammalian ancestors lost the SWS2 and $\mathrm{Rh} 2$ genes that encode visual pigments with absorption peaks in the short and medium wavelengths, respectively (Trezise \& Collin, 2005). This likely occurred because of the nocturnal lifestyle of mammalian ancestors that lost opsin genes as an adaptation to the scotopic environment (Jacobs, 2013).

Vertebrate opsin genes have been grouped into five classes according to opsin spectral sensitivity and absorption peak $\left(\lambda_{\max }\right.$; Yokoyama, 2002): LWS group (pigments with long-wavelength sensitivity; $\lambda_{\max }=510$ $570 \mathrm{~nm}$; also called MWS/LWS), Rh1 group (rhodopsins with $\lambda_{\max }=480-510 \mathrm{~nm}$ ), Rh2 group (opsins with $\lambda_{\text {max }}=$ 470-510 nm), SWS1 group (pigments with very short-

Daniela Maria Oliveira Bonci and Dora Fix Ventura, Departamento de Psicologia Experimental, Instituto de Psicologia, Universidade de São Paulo, São Paulo, Brazil. Daniela Maria Oliveira Bonci and Dora Fix Ventura, Núcleo de Neurociências e Comportamento, Universidade de São Paulo, São Paulo, Brazil. Maureen Neitz and Jay Neitz, University of Washington, Seattle, Washington, USA. Luiz Carlos de Lima Silveira, Núcleo de Medicina Tropical, Universidade Federal do Pará, Belém, Pará, Brazil and Instituto de Ciências Biológicas, Universidade Federal do Pará, Belém, Pará, Brazil. Correspondence regarding this article should be directed to: Daniela M. O. Bonci, Departamento de Psicologia Experimental, Instituto de Psicologia, Universidade de São Paulo, Av Prof. Mello Moraes, 1721 - Bloco A sala D9, São Paulo, São Paulo, 05508-030, Brasil. E-mail: dbonci@usp.br wavelength sensitivity; $\lambda_{\max }=360-430 \mathrm{~nm}$ ), and SWS2 group (pigments with short-wavelength sensitivity; $\lambda_{\max }$ $=440-460 \mathrm{~nm}$ ).

Most mammals have only two genes that encode photopigments that are responsible for color vision: LWS and SWS1. Marsupials (Arrese et al., 2005; Arrese, Hart, Thomas, Beazley, \& Shand, 2002), Old World monkeys, apes, humans, and most New World monkeys (Nathans, Thomas, \& Hogness, 1986) are exceptions among mammals because they have three genes responsible for color vision. In most New World monkeys, only a portion of females are trichromats, whereas males and a small population of females are dichromats. The exceptions to this pattern are the genus Alouatta, which is a full trichromat, and Aotus, which is a monochromat.

\section{Color vision}

Color vision depends on the existence of at least two types of photoreceptors that express visual pigments with different spectral absorbance peaks and a neural substrate capable of comparing the signals from these two photoreceptor types. This neural substrate comprises chromatic opponent channels that extend from the retina to higher visual centers. In dichromatic mammals, color vision is supported by two cone classes and one post-receptoral circuit, whereas trichromats have three different cone classes and two post-receptoral circuits. A few mammals are monochromats in both scotopic and photopic illumination because their vision is supported by a single class of rods and cones in these two conditions.

Classic psychophysical studies in humans demonstrated that spectral colors could be matched by the use of three different primary colors. Color-matching experiments used a bipartite field with a test color to 
be matched on one side and an adjustable mixture of three primary colors on the other side (Hunt, 1987). The fact that all of the colors discriminated by humans are matched using just three primary colors in the mixture is a consequence of the fact that the human retina has only three spectrally different cone classes (Hunt, 1987). Similar experiments can be performed in nonhuman mammals and other vertebrates using behavioral paradigms (Kelber, Vorobyev, \& Osorio, 2003). These behavioral experiments were performed in different mammals including New World monkeys (Mollon, Bowmaker, \& Jacobs, 1984), Old World monkeys (Kelber et al., 2003), and marsupials (Arrese, Beazley, $\&$ Neumeyer, 2006) to determine the dimensionality of their color vision. In mammals with three different cone opsins, behavioral experiments indicated trichromatic color vision supported by an opsin with an absorption peak in the ultraviolet spectral region in marsupials and violet region in many primates.

In specialized retinal cells, the apoprotein opsin covalently binds to the vitamin A derivative 11-cis retinal to form visual pigment molecules responsible for light absorption in the retina. The transduction process is initiated by the absorption of quanta of light by the photopigment followed by a phototransduction cascade. The final product is the transduction of light into a neural output.

Opsins are also found in specialized ganglion cells (i.e., intrinsically photosensitive ganglion cells) that contain melanopsin (Hattar, Liao, Takao, Berson, \& Yau, 2002; Provencio, Cooper, \& Foster, 1998; Provencio, Rodriguez, Jiang, Hayes, Moreira, \& Rollag, 2000). Melanopsins are related to circadian rhythms (Altimus et al., 2010; Berson, Dunn, \& Takao, 2002; Hattar et al., 2002; Ruby et al., 2002) and the pupillary light reflex (Gooley, Lu, Chou, Scammell, \& Saper, 2001; Güler et al., 2008; Park, Moura, Raza, Rhee, Kardon, \& Hood, 2011; Xue et al., 2011), among other functions.

\section{Primate color vision}

All living primates belong to the Order Primates, which comprises the Semiorders Strepsirhini and Haplorhini (Goodman et al., 1998). The Strepsirhini group is composed of lemurs (Suborder Lemuriformes), lorises, and bush babies (Suborder Loriforme). The Haplorhini group comprises tarsi (Suborder Tarsiiformes) and simians (Suborder Anthropoidea). The Anthropoidea group includes the Infraorder Platyrrhini ("flat nose"), which comprises New World monkeys (Superfamily Ceboidea), and Infraorder Catarrhini ("sharp nose"), which includes the Superfamily Cercopithecoidea with Old World monkeys and Family Hominidae, with gibbons and hominids, including humans.

Color vision among most New World monkeys represents an evolutionary intermediary between the dichromatic color vision typical of most mammals and routine trichromacy typical of Old World monkeys. In both Plathyrrini and Catharrini, genetic polymorphisms in the opsin gene on the X-chromosome gave rise to opsins that form LWS/MWS visual pigments, with peak sensitivities ranging from $\sim 510$ to $560 \mathrm{~nm}$. In Catharrini and Plathyrrini Alouatta, a gene duplication also occurred that placed two opsin genes on the $\mathrm{X}$ chromosome and, additionally, a largely unknown mechanism that segregates the expression of LWS and MWS opsin genes on the same X chromosome to separate populations of cones, thereby allowing males and females to both exhibit trichromatic color vision.

Most Plathyrrini species, however, have a single visual pigment gene on the $\mathrm{X}$ chromosome, but that gene exhibits allelic diversity. Because males have only one $\mathrm{X}$ chromosome, males of these species have dichromatic color vision mediated by the autosome-encoded SWS opsin and X chromosome-encoded LWS/MWS opsin. Females, in contrast, have two X chromosomes. During the early stages of embryogenesis, each cell undergoes a random process whereby only one $\mathrm{X}$ chromosome is retained as the active one, and the other $\mathrm{X}$ chromosome is inactivated (Lyon, 1961, 1962; Ohno, \& Hauschka, 1960; Okamoto, Otte, Allis, Reinberg, \& Heard, 2004). In females heterozygous for the $\mathrm{X}$ chromosome opsin allele, random $\mathrm{X}$ inactivation segregates the expression of the two opsin alleles to separate populations of cones, giving rise to LWS and MWS cones. Together with the autosome-encoded SWS opsin, this provides the photoreceptor basis for trichromacy in these animals. Females homozygous for the $\mathrm{X}$ chromosome opsin gene, like males of the species, will only have two cone types and exhibit dichromatic phenotypes similar to those found in males (Jacobs \& Neitz, 1985; Jacobs \& Neitz, 1987a; Hunt et al., 1998).

Some exceptions were observed in two species of howler monkey, Alouatta seniculus and Alouatta caraya, in which genetic analysis and electroretinography (ERG) showed that both males and females are trichromats (Jacobs, Neitz, \& Neitz, 1996; Silveira, Saito, Da Silva Filho, Bowmaker, Kremers, \& Lee, 2007). In one species of the owl monkey, Aotus trivirgatus, ERG, psychophysical analysis, and genetic analysis showed that this species is monochromatic (Jacobs, Deegan, Neitz, Crognale, \& Neitz, 1993).

The SWS cone opsin is encoded by a gene that is present on a chromosome that in humans is chromosome 7 (Nathans et al., 1986; Shimmin, Mai, \& Li, 1997). Thus, a major difference between LWS and MWS cones vs. SWS cones is that SWS cones express two copies of the SWS opsin gene, one from each autosome. In contrast, $\mathrm{L}$ and $\mathrm{M}$ cones express only one opsin gene, the one on the active $\mathrm{X}$ chromosome in females or the one on the only X chromosome in males. The SWS opsin gene polymorphisms identified to date have been shown to cause a loss of SWS cone function and do not originate spectral variants of SWS cone photopigments in the same animal as occurs with MWS/LWS genes. However, SWS opsin is not as well studied as MWS/ LWS opsins in studies of opsin gene polymorphisms. The present article considers that all animals have the 
SWS cone, with the exception of the monochromatic genus Aotus sp.

The gene that encodes the photopigment present in rods is located on chromosome 3 and composed of five exons (Nathans \& Hogness, 1984). Rods and their single visual pigment are the only active photoreceptors at low light levels; thus, all mammals are monochromats in these conditions. At intermediate light levels, rods and cones might be simultaneously active, and rods might have an impact on color vision (Buck, 2001). In the owl monkey, rod-cone interactions in the ganglion cell response have been found at relatively high light levels (Silveira, Lee, Kremers, Silva-Filho, Saito \& Kilavik, 2000; Saito, Lee, Kremers, Silveira, da Silva Filho, \& Kilavik, 2001).

\section{Selection of trichromacy among primates}

The explanation for trichromacy-positive selection among primates is an open discussion. Some hypotheses are related to diet. Some researchers defend the hypothesis of frugivory in which the need to discriminate ripe fruit among foliage favors the selection of trichromacy (Sumner \& Mollon, 2000a,b; Regan, Julliot, Simmen, Viénot, Charles-Dominque, \& Mollon, 2001).

To investigate the "diet rich in fruit hypothesis," Sumner \& Mollon (2000a,b) measured the reflectance spectra of many samples of ripe fruits eaten by catarrhine monkeys from Uganda and concluded that the degree of ripeness of many fruit species would be discernible by dichromatic primates, but a trichromatic consumer would have an advantage for most fruits.

An alternate hypothesis of herbivory postulates that trichromacy was selected because of the need to discriminate younger and reddish leaves among green foliage (Dominy \& Lucas, 2001; Dominy, Garber, Bicca-Marques, \& Azevedo-Lopes, 2003) or mature green leaves against old reddish brown leaves (Kremers, Silveira, Yamada, \& Lee, 1999).

To investigate the "diet rich in leaves hypothesis," Dominy et al. (2003) described the relationship between the historical biogeography of figs and palm trees and the pattern of color vision variation in primates. The existence of a heterogeneous group in which some females are trichromats and other females and all males are dichromats may be advantageous to the group because of the wide variations in the colors of fig and palm trees. After regional extinction of the palm and fig trees likely caused by climatic variations, trichromacy could have allowed the primates to explore the reddish immature and rich-protein leaves as a substitute for fruit. The observation of the dietary patterns of New World monkeys showed that the diet of the vast majority is based on insects and foliage. However, the vast majority of catarrhine primates feed on leaves.

To elucidate the selection of trichromacy among primates, specimens from two Platirrhine genera (Allouata and Brachyteles) whose food preference is predominantly leaves have been studied (Jacobs et al., 1996; Kremers et al., 1999; Talebi, Pope, Vogel, Neitz, \& Dominy, 2006). Allouata are trichromatic animals according to genetic and ERG experiments performed by Jacobs et al. (1996). However, Talebi et al. (2006) sequenced exons 3 and 5 of the opsin gene in 18 animals and found that Brachyteles are not full trichromats, instead following the same allelic variation found in other Platirrhini, with a population composed of dichromatic males, dichromatic females, and homozygous trichromatic females.

A possible conclusion that may be drawn from these studies is that trichromacy in primates is not related to dietary habits but rather to other environmental or genetic factors that potentially helped maintain this adaptation. Alternatively, the gene duplication that brought trichromacy to Old World monkeys is a lowprobability event (Jacobs et al., 1996). This question is still open, and color vision in New World monkeys is a topic for further research and discussion.

Fourteen genera of the three families of New World monkeys were studied in terms of spectral absorbance peak of their opsins. The methods used included ERG, single-unit extracellular recordings, microspectrophotometry, genetic inference, and in vitro measurements of the pigment expressed by the cones. These studies are summarized in Table 1.

In the past decades, after the descriptions of alleles present in different species of New World monkeys, a high frequency of three polymorphic alleles was observed in their X chromosome opsin genes. Because of this triallelic system, a proportion of heterozygous females can be trichromats. Some studies postulated that this triallelic system may have arisen from a single source (single-origin hypothesis) or independently in different lineages (multiple-origin hypothesis; Boissinot et al., 1998; Shyue et al., 1995). Exceptions to the triallelic system rule have been recently reported. Jacobs \& Deegan (2005) described the existence of five alleles in Callicebus moloch, and Soares et al. (2010) reported a fourth allele in Cebus apella. In other New World monkeys, a maximum of only three polymorphic allelic combinations has been found (Bowmaker, Mollon, \& Jacobs, 1983; Jacobs \& Deegan, 2003; Saito et al., 2005).

\section{L/M opsins in New World monkeys}

Opsins in New World monkeys can be classified into five types according to their absorbance peak $\left(\lambda_{\text {max }}\right)$ : P560 or P562 nm, P553 nm, P550 or P545 nm, P538 nm, and P535 or P530 nm. The opsin absorbance peak is determined by three amino acids located at sites 180 (serine [Ser] or alanine [Ala]), 277 (tyrosine [Tyr] or phenylalanine [Phe]), and 285 (threonine [Thr] or alanine [Ala]; Hiramatsu, Radlwimmer, Yokoyama, \& Kawamura, 2004; Kawamura, Hirai, Takenaka, Radlwimmer, \& Yokoyama, 2001; Neitz, Neitz, \& Jacobs, 1991; Williams, Hunt, Bowmaker, \& Mollon, 1992; Yokoyama \& Radlwimmer, 1999). The effects of these substitutions are cumulative, and the combined 
Table 1. Overview of published studies describing the spectral sensitivity peak of M/L opsins in New World monkeys

\begin{tabular}{|c|c|c|c|c|c|c|c|}
\hline Family & Genus & & & $\begin{array}{l}\text { ensitiv } \\
\text { WS co }\end{array}$ & & & Reference $^{*}$ \\
\hline \multirow{6}{*}{ Atelidae } & \multirow{2}{*}{ Ateles } & & & & 550 & 561 & 1 (ERG) \\
\hline & & \multicolumn{4}{|c|}{547} & 562 & $2(\mathrm{E})$ \\
\hline & Brachyteles & 530 & & & 550 & 562 & $3(\mathrm{I})$ \\
\hline & Lagothrix & & & 547 & & 562 & 1 (ERG) \\
\hline & \multirow{2}{*}{ Alouatta } & 530 & & & & 562 & 17 (ERG, I) \\
\hline & & 529 & & & 557 & & 23 (SUER, MSP) \\
\hline \multirow{4}{*}{ Pitheciidae } & \multirow{2}{*}{ Pithecia } & \multicolumn{3}{|c|}{537} & 563 & 565 & 4 (ERG) \\
\hline & & \multicolumn{3}{|c|}{535} & 550 & 562 & $5(\mathrm{I})$ \\
\hline & \multirow{2}{*}{ Callicebus } & 530 & 535 & 542 & 550 & 562 & 13 (ERG) \\
\hline & & & 535 & & 550 & 562 & $14(\mathrm{I})$ \\
\hline \multirow{19}{*}{ Cebidae } & \multirow{7}{*}{ Cebus } & & 534 & & & & 6 (MSP) \\
\hline & & & 536 & 549 & & 561 & 12 (ERG) \\
\hline & & 530 & & 545 & & & $7(\mathrm{E})$ \\
\hline & & 532 & & 545 & 550 & 560 & 18 (ERG, I) \\
\hline & & & 535 & & & 563 & 20 (SUER, I) \\
\hline & & & 535 & & 550 & 563 & 21 (SUER, MSP) \\
\hline & & & 535 & & & 563 & 22 (SUER) \\
\hline & \multirow{4}{*}{ Saimiri } & & 537 & & 550 & 565 & 8 (MSP) \\
\hline & & 532 & & 545 & 558 & & $9(\mathrm{E})$ \\
\hline & & & 536 & 548 & & 561 & 4 (ERG) \\
\hline & & & 538 & & 551 & 561 & 15 (ERG) \\
\hline & Saguinus & & & 545 & 557 & 563 & 4 (ERG) \\
\hline & Leontopithecus & & & 545 & 557 & & 4 (ERG) \\
\hline & Callimico & & & 543 & & 563 & $10(\mathrm{I})$ \\
\hline & \multirow{3}{*}{ Callithrix } & & & 543 & 556 & 563 & 11 (MSP) \\
\hline & & & 539 & & 553 & 561 & $9(\mathrm{E})$ \\
\hline & & & & 543 & & 563 & 19 (ERG) \\
\hline & Cebuella & & & & 556 & 563 & $10(\mathrm{I})$ \\
\hline & Aotinae & & & 543 & & & $\begin{array}{c}16 \text { (ERG, I, P) } \\
22 \text { (SUER) }\end{array}$ \\
\hline
\end{tabular}

*ERG, electroretinography; MSP, microspectrophotometry; E, in vitro measurements of cone expression; I, inferred from genetic analysis; P, psychophysics; SUER, single-unit extracellular recording. References: (1) Jacobs \& Deegan (2001); (2) Hiramatsu et al. (2005); (3) Talebi et al. (2006); (4) Jacobs \& Deegan (2003); (5) Boissinot et al. (1998); (6) Bowmaker et al. (1983); (7) Saito et al. (2005); (8) Mollon et al. (1984); (9) Kawamura et al. (2001); (10) Surridge \& Mundy (2002); (11) Travis et al. (1988); (12) Jacobs \& Neitz (1987b); (13) Jacobs \& Deegan (2005); (14) Bunce et al. (2011); (15) Jacobs, \& Neitz (1987a); (16) Jacobs et al. (1993); (17) Jacobs et al. (1996); (18) Soares et al. (2010); (19) Yeh et al. (1995); (20) Lee et al. (1996); (21) Lee et al. (2000); (22) Saito et al. (2001); (23) Saito et al. (2004). Modified from Jacobs (2007).

effect of these amino acids expressed by exons 3 (A180S) and 5 (Y277P and T285A) is associated with a progressive change in the peak of cone spectral sensitivity observed in the different phenotypes of a given primate species. Thus, predicting the absorbance curve of the photopigment is possible by combining these three amino acids at these positions (Asenjo, Rim, \& Oprian, 1994; Hunt, Williams, Bowmaker, \& Mollon, 1993; Neitz et al., 1991).

\section{Atelidae family}

The Atelidae Family comprises four genera and is represented by howler monkeys (Alouatta sp.), spider monkeys (Ateles sp.), muriquis (Brachyteles sp.), and woolly monkeys (Logothrix sp.). Visual pigments of different species of four Atelidae genera have been studied using ERG and genetic analysis. Spider monkeys (Hiramatsu, Tsutsui, Matsumoto, Aurrell, Fedigan, \& Kawamura, 2005; Jacobs \& Deegan, 2001), muriquis (Talebi et al., 2006), and woolly monkeys (Jacobs \& Deegan, 2001) follow the color vision rule found in New World monkeys in which all males and a fraction of females are dichromats, and some females are trichromats. The spectral sensitivity functions of the Atelidae species described in Table 1 are shown in Figure 1.

The most interesting feature found in the Atelidae Family is the presence of full tricromacy in Alouatta 
A.

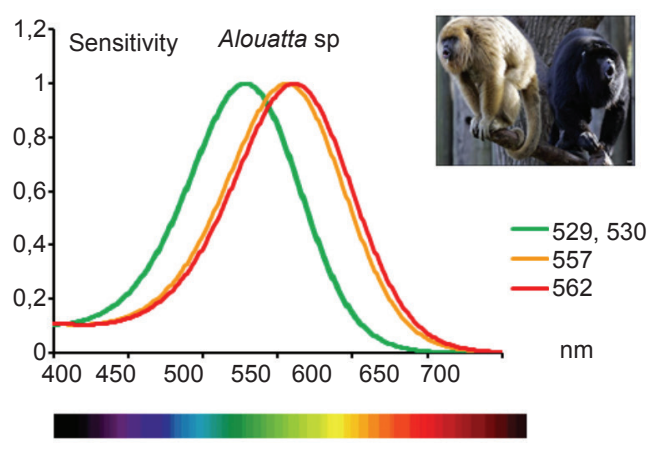

C.

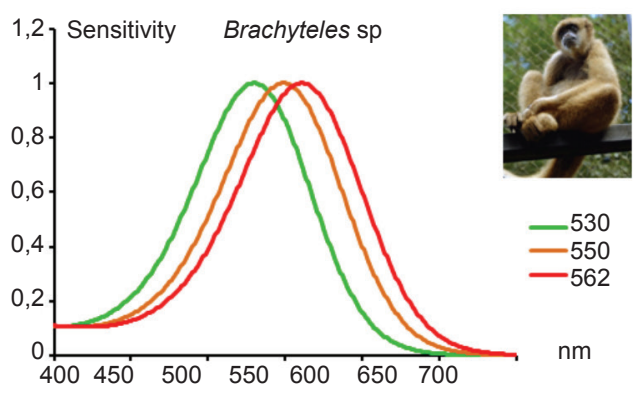

B.

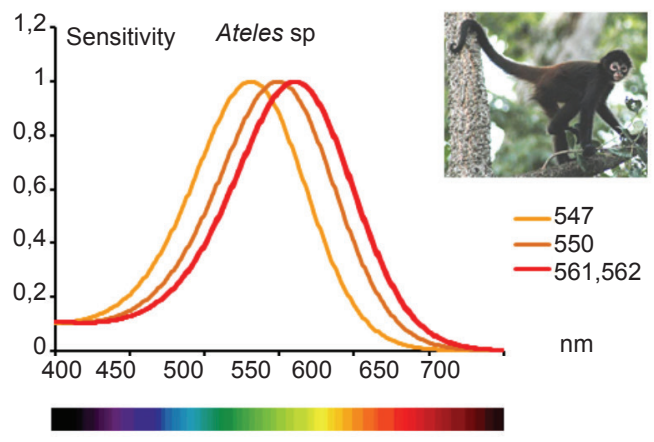

D.

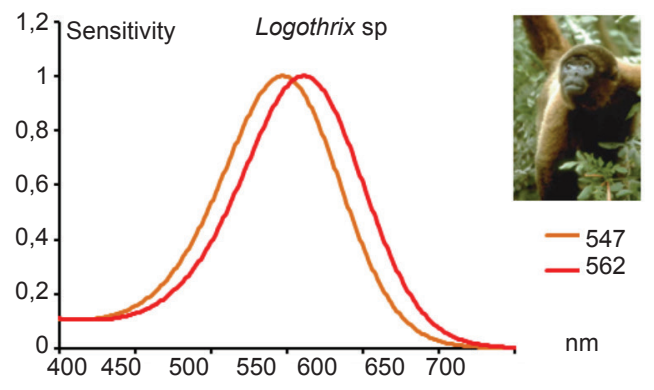

Figure 1. Summary of spectral sensitivity peaks described for LWS/MWS opsin in the Atelidae family. In Alouatta sp., two types of opsins were described with wavelength $(\lambda)$ peaks at 530 and $561 \mathrm{~nm}(\mathrm{~A})$. Both are expressed in the retina in males because of the fact that the LWS and MWS genes are present on the same X chromosome. In the other species, two different opsin genes were not found in males, only in some heterozygous females. Therefore, all males of these species are dichromats. In Ateles sp., the opsin peaks of four alleles were found at 547, 550, 561, and $562 \mathrm{~nm}$ (B). In Brachyteles sp., peaks were found at 530, 550, and $562 \mathrm{~nm}$ (C). In Logothrix sp., peaks were found at 547 and $562 \mathrm{~nm}$ (D). Graphs were prepared by Balazs Vince Nagy according to Stockman \& Sharpe (2000). Photograph sources: http://www.moreinterestingfacts.com/monkey-facts (A); http://www.factzoo. com/monkeys/spider-monkeys-jungle-acrobats-swingers.html (B); http://www.temmaistudo.com/curiosidades/o-que-e-muriqui (C); http://saveamericasforests.org/Yasuni/Biodiversity/Woolly\%20Monkey.html (D).

males. Jacobs et al. (1996) performed ERG and genetic experiments in two species of howler monkeys: $A$. caraya (one female and one male) and $A$. seniculus (one female). The results revealed full trichromacy in the three specimens studied. Kainz, Neitz, \& Neitz (1998) characterized locus control regions that corresponded to two MWS/LWS pigment genes in $A$. seniculus and $A$. caraya. The promoter sequence of both species was very similar, having one or two base differences between the howler genes. However, compared with human MWS and LWS genes, 10 base differences were found in howler genes. The low similarity between howler and human MWS and LWS genes in the promoter region indicates that human genes are not related to howler genes. This means that the acquisition of trichromacy was an independent event from the gene duplication that gave rise to the trichromacy of Old World monkeys. Recently, Silveira and colleagues (Saito, da Silva Filho, Lee, Bowmaker, Kremers, \& Silveira, 2004; Silveira et al., 2007) demonstrated trichromacy in Alouatta caraya using single-unit extracellular recordings from parafoveal retinal ganglion cells. They also used microspectrophotometry to show that only a single opsin is expressed by each cone, despite the presence of a locus control region for each $\mathrm{L}$ and $\mathrm{M}$ opsin gene on the same X chromosome. Finally, Araújo, Didonet, Araujo, Saletti, Borges, \& Pessoa (2008) provided behavioral evidence of trichromacy in both female and male howler monkeys. Unknown, however, is why trichromacy was selected after the primate divergence that gave rise to the New World monkeys group. The acquisition of monkey trichromacy is still an interesting open question.

\section{Pitheciidae family}

The Pitheciidae Family includes titis (Callicebus sp.), saki monkeys (Chiropotes sp. or Pithecia sp.), and uakaris (Cacajao sp.). Few studies have been published that described the genetics of color vision in this family. The spectral sensitivity functions of the Pitheciidae species described in Table 1 are shown in Figure 2. 
A.

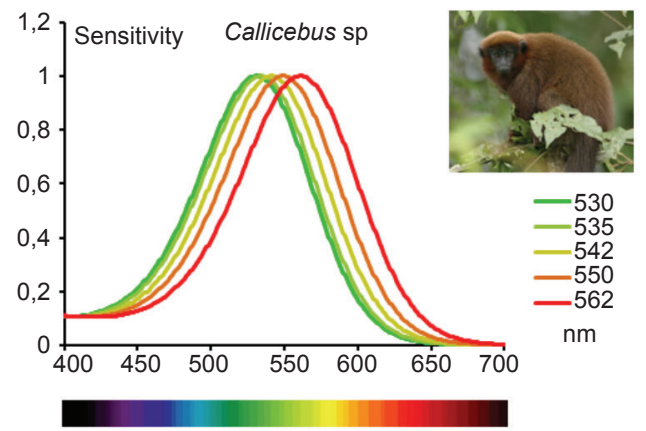

B.

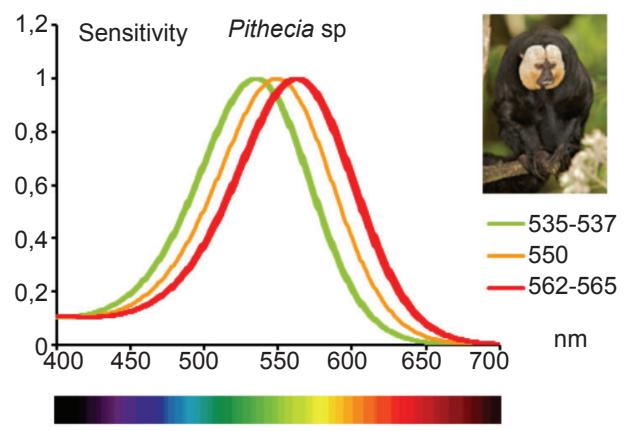

Figure 2. Summary of spectral sensitivity peaks described for genes that express L/M opsin in the Pitheciidae family. For all species, an $\mathrm{S}$ cone was assumed to be present. Both species described are dichromatic with the expression of only one of the alleles for the MWS/LWS opsin gene. In Callicebus sp., five types of opsin with $\lambda$ peaks at 530, 535, 542, 550, and 562 nm were described (A). In Pithecia sp., peaks were found at 537, 563, and $565 \mathrm{~nm}$ (B). Graphs were prepared by Balazs Vince Nagy according to Stockman \& Sharpe (2000). Photograph source: Los Amigos, Peru@ Joseph Tobias, http://www.neomorphus.com/ pictures/mammals/pages/callicebusmoloch.htm (A); Tino Poels, http://es.treknature.com/gallery/photo219193.htm (B).

Prior to the genetic results in dusky titi monkeys (Jacobs \& Deegan, 2005) that showed five different opsins, a three-allelic theory prevailed to explain the allelic variation of the New World monkey opsin gene. After L/MWS opsin gene sequencing in different species of New World monkeys (i.e., Boissinot et al., 1998), the X-linked opsin locus was presumed to have three high-frequency polymorphic alleles that encoded three pigments with different spectral sensitivity maxima $\left(\lambda_{\max }\right)$ in New World monkeys. To test this hypothesis, Boissinot et al. (1998) evaluated the opsin genes from 16 male saki monkeys and identified three alleles (P535, P550, and P562), corroborating the three-allelic theory. Jacobs \& Deegan (2003) performed ERG in two whitefaced Saki monkeys (Pithecia pithecia), indicating the presence of one pigment with a $\lambda_{\text {max }}$ of $565 \mathrm{~nm}$ in the dichromat male and two pigments with a $\lambda_{\max }$ of 537 and $537 \mathrm{~nm}$ in the trichromatic female.

Jacobs \& Deegan (2005) evaluated the allelic variation of opsin genes in 52 captive dusky monkeys (Callicebus moloch) using ERG. The results revealed five different opsins with peak absorption at 530, 536, 542,551 , and $560 \mathrm{~nm}$ expressed by this species. This was the first time that more than three polymorphic alleles were described in a monkey species.

Bunce et al. (2011) evaluated the opsin genes in a wild group of the Pitheciidae family, the brown titi monkey (Callicebus brunneus). They found three allelic variations with pigments with peak absorption at 535 , 550 , and $562 \mathrm{~nm}$. The results, however, did not agree with the variation described by Jacobs \& Deegan (2005), possibly because of the small number of samples that were analyzed or inter-species variations.

\section{Cebidae family}

The Cebidae Family comprises the genera Cebus (capuchin monkey), Saimiri (squirrel monkey), Aotus (owl monkey), Saguinus (tamarin), Leontopithecus (lion tamarin), Callimico (Goeldi's marmoset), Cebuella (pygmy marmoset), and Callithrix (marmoset). The spectral sensitivity functions of the Cebidae Family described in Table 1 are shown in Figure 3.

The owl monkey is the only monochromat among New World monkeys. Studying this primate in comparison with closely related trichromatic species may provide a better understanding of the importance of color vision for this mammalian group.

Monochromatism in the Aotus genus has been demonstrated by the presence of only one MWS/LWS gene on the X chromosome, behavioral studies (Jacobs et al., 1993), and single-unit extracellular recording of retinal ganglion cells (Saito et al., 2001). Aotus has an impaired SWS gene caused by a two-nucleotide insertion followed by a single deletion that shifts the reading frame and introduces a stop codon at exon 4 of the SWS-cone opsin gene (Jacobs et al., 1996; Levenson, Fernandez-Duque, Evans, \& Jacobs, 2007). The loss of the functional SWS opsin in the owl monkeys was first thought to be related to its nocturnal activity (Jacobs et al., 1996). However, both nocturnal (A. nancymaae) and cathemeral (A. azarai species) species (FernandezDuque, 2003; Fernandez-Duque \& Erkert, 2006) exhibit mutations in the SWS gene, making them potentially monochromatic (Levenson et al., 2007). In conclusion, the monochromacy found in owl monkeys likely predates the radiation of Aotus, thus obviating its linkage to nocturnality (Tan, Yoder, Yamashita, \& Li, 2005).

Two other genera from the Cebidae Family, Cebus and Saimiri, have been especially interesting for color vision research, reflected by the numerous studies of their visual system. The similarities between the brains of capuchins and macaques associated with the multiplicity of color vision phenotypes makes the genus Cebus a valuable model for studying many aspects of vision including color vision in primates and its morphological and physiological substrates. 

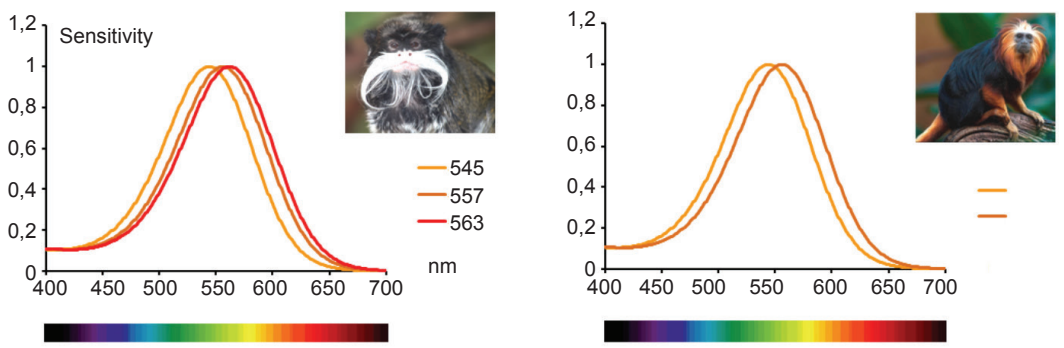

C.
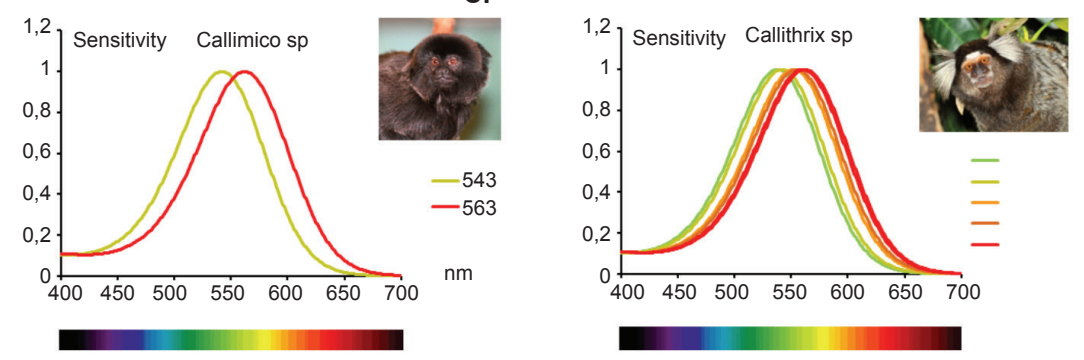

E.
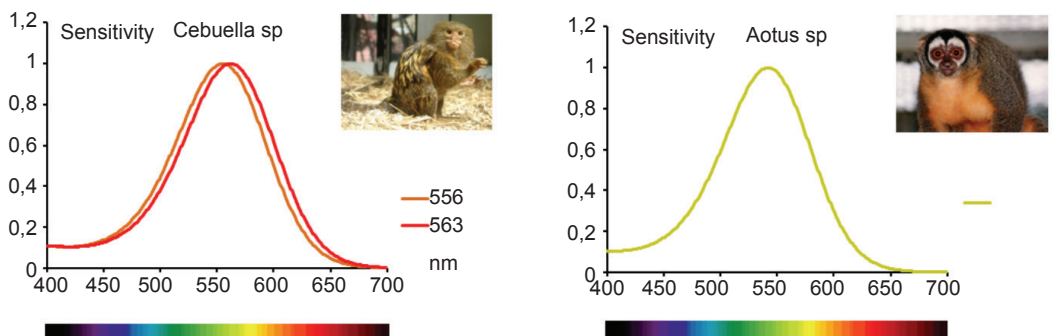

G.
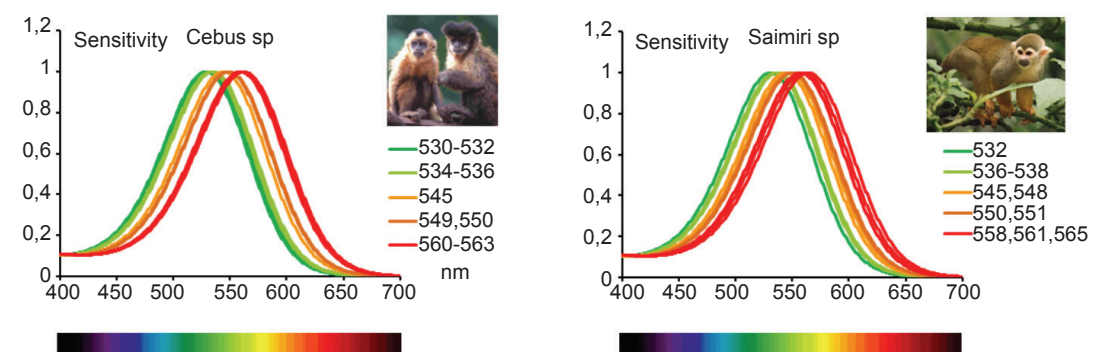

Figure 3. Summary of spectral sensitivity peak of polymorphisms described for genes that express LWS/MWS opsin in the Cebidae family. For all species, an S cone was assumed to be present with the exception of Aotus sp., which lost the SWS opsin (see text). According to the literature (Table 1), all species are dichromatic with the expression of only one of the alleles of the LWS/MWS opsin gene. In Saguinus sp., three types of opsin with wavelength ( $\lambda$ ) peaks at 545, 557, and 563 nm were described (A). In Leontopithecus sp., peaks were found at 545 and $557 \mathrm{~nm}$ (B). In Callimico sp., peaks were found at 543 and $563 \mathrm{~nm}$ (C). In Callithrix sp., alleles had absorption peaks at 539, 543, 553, 556, 561, and $563 \mathrm{~nm}$ (D). In Cebuella sp., peaks were found at 556 and $563 \mathrm{~nm}(\mathrm{E})$. In the monochromatic monkey Aotus sp., the single allele found had a peak at $543 \mathrm{~nm}(\mathrm{~F})$. In Cebus sp., peaks were found at 530, 534, 536, 545, 549, 550, 560, and $561 \mathrm{~nm}$ (G). In Saimiri sp., peaks were found at 532, 536, $538,545,550,551,558,561$, and $565 \mathrm{~nm}(\mathrm{H})$. Graphs were prepared by Balazs Vince Nagy according to Stockman \& Sharpe (2000). Photograph sources: Brocken Inaglory, edited by Fir0002, http://en.wikipedia.org/wiki/File:Tamarin_portrait_2_edit2. jpg\#filelinks 
Similarities between the visual systems of capuchin monkeys (Cebus sp.) and Old World monkeys have been described in several studies. Some of these likenesses can be observed in retinal morphology (Silveira, Picanço-Diniz, Sampaio, \& Oswaldo-Cruz, 1989; de Lima, Silveira, \& Perry, 1993, 1996; Silveira, Yamada, Perry, \& Picanço-Diniz, 1994; Silveira, Lee, Yamada, Kremers, \& Hunt, 1998; Silveira et al., 1999; Yamada, Silveira, \& Perry, 1996a; Yamada, Silveira, Gomes, \& Lee, 1996b; Andrade-da-Costa \& Hokoç, 2000; dos Reis, de Carvalho, Saito, \& Silveira, 2002; Finlay et al., 2008), retinal physiology (Lee, Silveira, Yamada, \& Kremers, 1996; Silveira et al., 1999; Lee et al., 2000), brain size, cleavage patterns, and the relative position of homologous visual areas (Gattass, Gross, \& Sandell, 1981; Gattass, Sousa, \& Rosa, 1987; Rosa, Sousa, \& Gattass, 1988; Fiorani, Gattas, Sousa, \& Rosa, 1989), and the visual cortex (Gattass et al., 1981, 1987; Fiorani, Gattass, Rosa, \& Sousa, 1989; Rosa, Soares, Fiorani, \& Gattass, 1993).

The genus Saimiri is remarkably important for research on monkey color vision. Among the first works on color vision in New World monkeys were important studies performed in squirrel monkeys. In the 1980 s, within-species variation was demonstrated, with significant sex-related differences in color sensitivity in Saimiri sp monkeys found in behavioral (Jacobs, 1977, 1984), microspectrophotometric (Jacobs, Bowmaker, \& Mollon, 1981), and electrophysiological (Jacobs, 1972, 1983; Neitz \& Jacobs, 1984) studies. In squirrel monkeys with different geographical origins, the same gender variations in color vision were observed (Jacobs \& Blakeslee, 1984). Color vision variations may be explained by the presence of polymorphic pigments in the monkey retina (Mollon et al., 1984) that are encoded by polymorphic genes on the $\mathrm{X}$ chromosome (Jacobs \& Neitz, 1985, 1987a). For a review of the extensive literature on squirrel monkey color vision, see Jacobs (2008).

The most recent work on the genetics of color vision in New World monkeys was performed in Saimiri. After behavioral color vision tests were conducted in adult squirrel monkeys (Saimiri sciureus; Mancuso, Neitz, \& Neitz, 2006), gene therapy was performed in these animals (Mancuso et al., 2009) in which the researchers sought to induce the expression of the LWS gene. The gene to be introduced was carried by a viral vector that penetrated the MWS cones. An attempt was made to turn a dichromatic animal, which did not have the LWS gene, into a trichromatic phenotype. The results showed that treated adult monkeys were able to discriminate colors previously not discriminated during the behavioral test. These results provide hope for the treatment of neuropathies that cause retinal degeneration.

The genus Saguinus sp. is represented by the tamarin whose color vision follows the same pattern as New World monkeys. Three spectral sensitivity classes of photopigments have been described for tamarins $\left(\lambda_{\max }\right.$ $=541-548,556-557$, and $562-565 \mathrm{~nm}$ ). Color vision in
Saguinus sp. was studied using behavioral tests (Jacobs, Neitz, \& Crognale, 1987), electrophysiology with ERG flicker photometry (Jacobs et al., 1987; Jacobs \& Deegan, 2003; Neitz et al., 1991; Surridge \& Mundy, 2002), and genetic analysis to predict the amino acid sequences of the photopigments (Shyue et al., 1998; Surridge, Suárez, Buchanan-Smith, Smith, \& Mundy, 2005).

Three different alleles (543, 556, and 563) were found in two species of tamarins, Saguinus fuscicollis and Saguinus labiatus, using genetic experiments (Surridge \& Mundy, 2002). The next year, Jacobs \& Deegan (2003) used ERG flicker photometry to measure spectral sensitivity in cotton tamarins (Saguinus oedipus) and golden-handed tamarins (Saguinus midis) and found the presence of alleles with absorption peaks around 543-548, 557, and $565 \mathrm{~nm}$ in Saguinus oedipus and 542 and $557 \mathrm{~nm}$ in Saguinus midis. All photopigment peaks were close to the three alleles previously described by Surridge \& Mundy (2002).

The Callithrix genus comprises marmosets. Travis, Bowmaker, \& Mollon (1988) used microspectrophotometry to evaluate color vision in the common marmoset Callithrix jacchus jacchus and found three different alleles with absorption peaks at 545, 559, and $567 \mathrm{~nm}$. A decade later, Shyue et al. (1998) described three alleles for the same marmoset species, with absorption peaks around 543, 556, and 562 $\mathrm{nm}$ using sequencing analysis. Kawamura et al. (2001) studied Callithrix jacchus jacchus using molecular biology techniques to better understand red-green color vision in marmosets. They screened the genomic DNA library of the common marmoset and conducted Southern hybridization and fluorescence in situ hybridization (FISH). They localized the photopigment genes to the $\mathrm{X}$ chromosome and obtained more accurate estimates of the $\lambda_{\max }$ values of the three LWS/MWS pigments through an in vitro assay using cultured cells. The three photopigments described by Kawamura et al. (2001) had absorption peaks at 539,553 , and $561 \mathrm{~nm}$, in contrast to the findings by Travis et al. (1988). One year later, Surridge \& Mundy (2002) evaluated the same species, Callithrix jacchus jacchus and Callithrix geoffroyi, and found three alleles in both species with absorption peaks around 543, 556, and $563 \mathrm{~nm}$. The method used was sequencing and the deduction of the main amino acids related to the spectral absorption peak curve. The reason for the differences in the results obtained by the different groups with regard to the alleles present in marmosets might be explained by the accuracy of each technique used to study visual pigments.

Few works have been published about three other genera from the Cebidae family, Leonthopitecus, Callimico, and Cebuella. Surridge \& Mundy (2002) examined Leontopithecus sp. (golden lion tamarin) using ERG flicker photometry and found three alleles with absorption peaks around 543, 556, and $563 \mathrm{~nm}$. Jacobs \& Deegan (2003) found two photopigments with absorption peaks around 546 and $555 \mathrm{~nm}$. Surridge \& 
Mundy (2002) also analyzed the polymorphic alleles present in Callimico (Goeldi's marmoset) and Cebuella (pygmy marmoset). In Callimico, two alleles were found with absorption peaks around 543 and $563 \mathrm{~nm}$. In Cebuella, two photopigments were described, with 556 and $563 \mathrm{~nm}$ absorption peaks.

\section{Conclusion}

The variety of color vision genotypes and phenotypes present in New World monkeys makes this group very interesting for studying the evolution of color vision and the processes that selected trichromatic color vision among primates. The diversity of opsin in the Infraorder Platyrrhini is presented in Table 2.

Table 2. Opsin types according to the spectral absorption peak, described for Infraorder Platyrrhini

\begin{tabular}{lccc}
\hline Family & MWS (nm) & $\begin{array}{c}\text { MWS / LWS } \\
(\mathbf{n m})\end{array}$ & LWS (nm) \\
\hline Atelidae & 529,530 & $547,550,557$ & 561,562 \\
& & 542,550 & $562,563,565$ \\
Pithecidae & $530,535,537$ & & $560,561,563$, \\
Cebidae & $530,532,534$, & $543,545,548$, & 565 \\
& $535,536,537$, & $549,550,551$, & 55,557, \\
& 538,539 & 553,556, & 558 \\
\hline
\end{tabular}

The comparison of the LWS and MWS gene sequences in New World monkeys indicates a more recent gene duplication process compared with Old World monkeys (Hunt et al., 1998; Kainz et al., 1998; Dulai et al., 1999). Comparisons of the LWS and MWS genes and upstream regions of both genes reveal a larger divergence in Old World monkeys than in howler monkeys, indicating that gene duplication occurred at the base of the Old World monkeys' lineage $~ 40$ million years ago (Goodman et al., 1998; Dulai et al., 1999).

In New World male monkeys, trichromacy is present only in howler monkeys (Jacobs et al., 1996), but trichromacy can occur in some females if two different gene alleles are expressed. The control of gene expression in Alouatta has been found to differ from Old World monkeys. In Alouatta, two Locus Control Regions (LCRs) are found, one at the LWS gene and another at the MWS gene (Dulai et al., 1999), in contrast to Old World monkeys that have only one LCR on the $\mathrm{X}$ chromosome, located upstream of the LWS gene. The function of the LCR is to determine and segregate the expression of LWS and MWS genes in each cone (Wang et al., Smallwood et al., 2002). The mechanism of the control of opsin gene expression in New World monkeys with two LCRs remains unknown. One hypothesis is that the second LCR upstream of the MWS gene is nonfunctional, so the control mechanism for the expression of the LWS and MWS genes would be the same as that found in Old World monkeys (Jacobs, 2008).

In conclusion, full trichromacy in primates appears to have arisen at least twice in the course of primate evolution in both Old World and New World primates, at the same time that it did not occur in almost all other mammalian branches (but see the recent discoveries on marsupials mentioned above). Trichromacy is a form of vision that comprises color discrimination in a tridimensional space formed by three orthogonal axes. Both full and partial trichromacy appears to be particularly advantageous for primate behavior. Color vision is particularly helpful for quick object discrimination and may have evolved in relation to several aspects of primate feeding behavior. Color vision also aids in efficiently updating the memory of visual scenes and may be particularly helpful for a mammalian group with a sophisticated visual system, such as primates.

\section{Acknowledgements}

This project received financial support from FINATEC, CAPES (CAPES/PROCAD 2007 Proj. 187 to DFV and LCLS), CNPq, and FAPESP (Projeto Temático \#2008/58731-2 and 2009/06026-6 to DFV). DMOB has a FAPESP postdoctoral fellowship (\#2011/17423-6). LCLS and DFV are CNPq research fellows.

\section{References}

Altimus, C. M., Güler, A. D., Alam, N. M., Arman, A. C., Prusky, G. T., Sampath, A. P., \& Hattar, S. (2010). Rod photoreceptors drive circadian photoentrainment across a wide range of light intensities. Nature Neuroscience, 13(9), 1107-1112.

Andrade da Costa, B. L. S., \& Hokoç, J. N. (2000). Photoreceptor topography of the retina in the New World monkey Cebus apella. Vision Research, 40(18), 2395-2409.

Araujo, A. C., Didonet, J. J., Araujo, C. S., Saletti, P. G., Borges, T. R. J., \& Pessoa, V. F. (2008). Color vision in the black howler monkey (Alouatta caraya). Visual Neuroscience, 25(3), 243-248.

Arrese, C. A., Beazley, L. D., \& Neumeyer, C. (2006). Behavioural evidence for marsupial trichromacy. Current Biology, 16(6), R193-R194.

Arrese, C. A., Hart, N. S., Thomas, N., Beazley, L. D., \& Shand, J. (2002). Trichromacy in Australian marsupials. Current Biology, 12(8), 657-660.

Arrese, C. A., Oddy, A. Y., Runham, P. B., Hart, N. S., Shand, J., Hunt, D. M., \& Beazley, L. D. (2005). Cone topography and spectral sensitivity in two potentially trichromatic marsupials, the quokka (Setonix brachyurus) and quenda (Isoodon obesulus). Proceedings, Biological Sciences, 272(1565), 791-796.

Asenjo, A. B., Rim, J., \& Oprian, D. D. (1994). Molecular determinants of human red/green color discrimination. Neuron, 12(5), 1131-1138.

Berson, D. M., Dunn, F. A., \& Takao, M. (2002). Phototransduction by retinal ganglion cells that set the circadian clock. Science, 295(5557), 1070-1073.

Boissinot, S., Tan, Y., Shyue, S. K., Schneider, H., Sampaio, I., Neiswanger, K., ... Li, W. H. (1998). Origins and antiquity of $\mathrm{X}$-linked triallelic color vision systems in New World monkeys. Proceedings of the National Academy of Sciences of the United States of America, 95(23), 13749-13754.

Bowmaker, J. K., Mollon, J. D., \& Jacobs, G. H. (1983). Microspectrophotometric measurements of Old and New world species of monkeys. In J. D. Mollon, \& L. T. Sharpe (Eds.), Colour vision: physiology and psychophysics (pp. 56-68). London: Academic Press.

Buck, S. L. (2001). What is the hue of rod vision? Color Research and Application, 26(Suppl.), S57-S59.

Bunce, J. A., Isbell, L. A., Neitz, M., Bonci, D., Surridge, A. K. Jacobs, G. H., \& Smith, D. G. (2011). Characterization of opsin gene alleles affecting color vision in a wild population of titi 
monkeys (Callicebus brunneus). American Journal of Primatology, 73(2), 189-196.

de Lima, S. M. A., Silveira, L. C. L., \& Perry, V. H. (1993). The M-ganglion cell density gradient in New-World monkeys. Brazilian Journal of Medical and Biological Research, 26(9), 961-964.

de Lima, S. M. A., Silveira, L. C. L., \& Perry, V. H. (1996). Distribution of $\mathrm{M}$ retinal ganglion cells in diurnal and nocturnal New World monkeys. Journal of Comparative Neurology, 368(4), 538-552.

Dominy, N. J., \& Lucas, P. W. (2001). Ecological importance of trichromatic vision to primates. Nature, 410(6826), 363-366.

Dominy, N. J., Garber, P. A., Bicca-Marques, J. C., \& Azevedo-Lopes, M. A. D. (2003). Do female tamarins use visual cues to detect fruit rewards more successfully than do males? Animal Behaviour, 66(5), 829-837.

dos Reis, J. W. L., de Carvalho, W. A., Saito, C. A., \& Silveira, L. C. L. (2002). Morphology of horizontal cells in the retina of the capuchin monkey, Cebus apella: How many horizontal cell classes are found in dichromatic primates? Journal of Comparative Neurology, 443(2), 105-123.

Dulai, K. S., von Dornum, M., Mollon, J. D. \& Hunt, D. M. (1999). The evolution of trichromatic color vision by opsin gene duplication in New World and Old World primates. Genome Research, 9(7), 629-638.

Fernandez-Duque, E. (2003). Influences of moonlight, ambient temperature, and food availability on the diurnal and nocturnal activity of owl monkeys (Aotus azarai). Behavioral Ecology and Sociobiology, 54, 431-440.

Fernandez-Duque, E., \& Erkert, H. G. (2006). Cathemerality and lunar periodicity of activity rhythms in owl monkeys of the Argentinian Chaco. Folia Primatologica (Basel), 77(1-2), 123-138.

Finlay, B. L., Franco, E. C. S., Yamada, E. S., Crowley, J. C., Parsons, M., Muniz, J. A., \& Silveira, L. C. (2008). Number and topography of cones, rods and optic nerve axons in New and Old World primates. Visual Neuroscience, 25(3), 289-299.

Fiorani, M., Jr., Gattass, R., Rosa, M. G. P., \& Sousa, A. P. B. (1989). Visual area MT in the Cebus monkey: Location, visuotopic organization, and variability. Journal of Comparative Neurology, 287(1), 98-118

Gattass, R., Gross, C. G., \& Sandell, J. H. (1981). Visual topography of V2 in the macaque. Journal of Comparative Neurology, 201(4), 519-539.

Gattass, R., Sousa, A. P. B., \& Rosa, M. G. P. (1987). Visual topography of V1 in the Cebus monkey. Journal of Comparative Neurology, 259(4), 529-548.

Goodman, M., Porter, C. A., Czelusniak, J., Page, S. L., Schneider, H., Shoshani, J., ... Groves, C. P. (1998). Toward a phylogenetic classification of primates based on DNA evidence complemented by fossil evidence. Molecular Phylogenetics and Evolution, 9(3), 585-598.

Gooley, J. J., Lu, J., Chou, T. C., Scammell, T. E., \& Saper, C. B. (2001). Melanopsin in cells of origin of the retinohypothalamic tract. Nature Neuroscience, 4(12), 1165.

Güler, A. D, Ecker, J. L., Lall, G. S., Haq, S., Altimus, C. M., Liao, H. W., ... Hattar, S. (2008). Melanopsin cells are the principal conduits for rod-cone input to non-image-forming vision. Nature, 453(7191), 102-105.

Hart, N. S., \& Hunt, D. M. (2007). Avian visual pigments: Characteristics, spectral tuning, and evolution. American Naturalist, 169(Suppl. 1), S7-S26.

Hattar, S., Liao, H. W., Takao, M., Berson, D. M., \& Yau, K. W. (2002). Melanopsin-containing retinal ganglion cells: Architecture, projections, and intrinsic photosensitivity. Science, 295(5557), 1065-1070

Hiramatsu, C., Radlwimmer, F. B., Yokoyama, S., \& Kawamura, S. (2004). Mutagenesis and reconstitution of middle-to-long-wavesensitive visual pigments of New World monkeys for testing the tuning effects of residues at sites 229 and 233. Vision Research, 44, 2225-2231.

Hiramatsu, C., Tsutsui, T., Matsumoto, Y., Aurrell, F., Fedigan, L. M., \& Kawamura, S. (2005). Color-vision polymorphism in wild capuchins (Cebus capuchinus) and spider monkeys (Ateles geoffroyi) in Costa Rica. American Journal of Primatology, 67(4), 447-461.
Hunt, D. M., Dulai, K. S., Cowing, J. A., Julliot, C., Mollon, J. D., Bowmaker, J., ... Hewett-Emmett, D. (1998). Molecular evolution of trichromacy in primates. Vision Research, 38(21), 3299-3306.

Hunt, D. M., Williams, A. J., Bowmaker, J. K., \& Mollon, J. D. (1993). Structure and evolution of the polymorphic photopigment gene of the marmoset. Vision Research, 33(2), 147-154.

Hunt, R. W. G. (1987). Measuring colour. Chichester: Ellis Horwood. Jacobs, G. H., Deegan, J. F., 2nd, Neitz, J., Crognale, M. A., \& Neitz, M. (1993). Photopigments and color vision in the nocturnal monkey, Aotus. Vision Research, 33(13), 1773-1783.

Jacobs, G. H. (1972). Increment-threshold spectral sensitivity in the squirrel monkey. Journal of Comparative and Physiological Psychology, 79(3), 425-431.

Jacobs, G. H. (1977). Visual sensitivity: significant within-species variations in a nonhuman primate. Science, 197(4302), 499-500.

Jacobs, G. H. (1983). Differences in spectral response properties of LGN cells in male and female squirrel monkeys. Vision Research, 23(5), 461-468.

Jacobs, G. H. (1984). Within-species variations in visual capacity among squirrel monkeys (Saimiri sciureus): Color vision. Vision Research, 24(10), 1267-1277.

Jacobs, G. H. (2007). New world monkeys and color. International Journal of Primatology, 28, 729-759.

Jacobs, G. H. (2008). Primate color vision: A comparative perspective. Visual Neuroscience, 25(5-6), 619-633.

Jacobs, G. H. (2013). Losses of functional opsin genes, shortwavelength cone photopigments, and color vision--a significant trend in the evolution of mammalian vision. Visual Neuroscience, 30(1-2), 39-53.

Jacobs, G. H., \& Blakeslee, B. (1984). Individual variations in color vision among squirrel monkeys (Saimiri sciureus) of different geographical origins. Journal of Comparative Psychology, 98(4), 347-357.

Jacobs, G. H., \& Deegan, J. F., 2nd (2001). Photopigments and color vision in New World monkeys from the family Atelidae. Proceedings, Biological Sciences, 268(1468), 695-702.

Jacobs, G. H., \& Deegan, J. F., 2nd (2003). Cone pigment variations in four genera of New World monkeys. Vision Research, 43(3), 227236.

Jacobs, G. H., \& Deegan, J. F., 2nd (2005). Polymorphic New World monkeys with more than three $\mathrm{M} / \mathrm{L}$ cone types. Journal of the Optical Society of America A: Optics, Image, Science and Vision, 22(10), 2072-2080.

Jacobs, G. H., \& Neitz, J. (1985). Color vision in squirrel monkeys: Sex-related differences suggest the mode of inheritance. Vision Research, 25(1), 141-143.

Jacobs, G. H., \& Neitz, J. (1987a). Inheritance of color vision in a New World monkey (Saimiri sciureus). Proceedings of the National Academy of Sciences of the United States of America, 84(8), 25452549.

Jacobs, G. H., \& Neitz, J. (1987b). Polymorphism of the middle wavelength cone in two species of South American monkey: Cebus apella and Callicebus moloch. Vision Research, 27(8), 1263-1268.

Jacobs, G. H., Bowmaker, J. K., \& Mollon, J. D. (1981). Behavioural and microspectro-photometric measurements of colour vision in monkeys. Nature, 292(5823), 541-543.

Jacobs, G. H., Neitz, J., \& Crognale, M. (1987). Color vision polymorphism and its photopigment basis in a callitrichid monkey (Saguinus fuscicollis). Vision Research, 27(12), 2089-2100.

Jacobs, G. H., Neitz, M., \& Neitz, J. (1996). Mutations in S-cone pigment genes and the absence of color vision in two species of nocturnal primate. Proceedings, Biological Sciences, 263(1371), 705-710.

Kainz, P. M., Neitz, J., \& Neitz, M. (1998). Recent evolution of uniform trichromacy in a New World monkey. Vision Research, 38(21), 3315-3320.

Kawamura, S., Hirai, M., Takenaka, O., Radlwimmer, F. B., \& Yokoyama, S. (2001). Genomic and spectral analyses of long to middle wavelength-sensitive visual pigments of common marmoset (Callithrix jacchus). Gene, 269(1-2), 45-51.

Kelber, A., Vorobyev, M., \& Osorio, D. (2003). Animal colour vision: Behavioural tests and physiological concepts. Biological Reviews of the Cambridge Philosophical Society, 78(1), 81-118. 
Kremers, J., Silveira, L. C. L., Yamada, E. S., \& Lee, B. B. (1999). The ecology and evolution of primate colour vision. In: K. R. Gegenfurtner, \& L. T. Sharpe (Eds.), Color vision: from genes to perception (pp. 123-142). Cambridge, England: Cambridge University Press

Lee, B. B., Silveira, L.C.L., Yamada, E.S., \& Kremers, J. (1996). Parallel pathways in the retina of Old and New World primates. Revista Brasileira de Biologia, 56(Suppl. 1, Pt. 2), 323-338.

Lee, B. B., Silveira, L. C. L., Yamada, E. S., Hunt, D. M., Kremers, J., Martin, P. R., ... da Silva-Filho, M. (2000). Visual response of ganglion cells of a New-World primate, the capuchin monkey, Cebus apella. Journal of Physiology (London), 528(3), 573-590.

Levenson, D. H., Fernandez-Duque, E., Evans, S., \& Jacobs, G. H. (2007). Mutational changes in S-cone opsin genes common to both nocturnal and cathemeral Aotus monkeys. American Journal of Primatology, 69(7), 757-765.

Lyon, M. F. (1961). Gene action in the X-chromosome of the mouse (Mus musculus L.). Nature, 190, 372-373.

Lyon, M. F. (1962). Sex chromatin and gene action in the mammalian X-chromosome. American Journal of Human Genetics, 14, 135148.

Mancuso, K., Hauswirth, W. W., Li, Q., Connor, T. B., Kuchenbecker, J. A., Mauck, M., ... Neitz, M. (2009). Gene therapy for red-green colour blindness in adult primates. Nature, 461(7265), 784-787.

Mancuso, K., Neitz, M., \& Neitz, J. (2006). An adaptation of the Cambridge Colour Test for use with animals. Visual Neuroscience, 23, 695-701.

Mollon, J. D., Bowmaker, J. K., \& Jacobs, G. H. (1984). Variations of colour vision in a New World primate can be explained by polymorphism of retinal photopigments. Proceedings of the Royal Society of London B. Biological Sciences, 222, 373-399.

Nathans, J., \& Hogness, D. S. (1984). Isolation and nucleotide sequence of the gene encoding human rhodopsin. Proceedings of the National Academy of Sciences of the United States of America, 81(15), 4851-4855.

Nathans, J., Thomas, D., \& Hogness, D. S. (1986). Molecular genetics of human color vision: The genes encoding blue, green, and red pigments. Science, 232(4747), 193-202.

Neitz, J., \& Jacobs, G. H. (1984). Electroretinogram measurements of cone spectral sensitivity in dichromatic monkeys. Journal of the Optical Society of America A, 1, 1175-1180.

Neitz, M., Neitz, J., \& Jacobs, G. H. (1991). Spectral tuning of pigments underlying red-green color vision. Science, 252, 971-974.

Ohno, S., \& Hauschka, T. S. (1960). Allocycly of the X-chromosome in tumors and normal tissues. Cancer Research, 20, 541-545.

Okamoto, I., Otte, A. P., Allis, C. D., Reinberg, D., \& Heard, E. (2004). Epigenetic dynamics of imprinted $X$ inactivation during early mouse development. Science, 303(5658), 644-649.

Park, J. C., Moura, A. L., Raza, A. S., Rhee, D. W., Kardon, R. H., \& Hood, D. C. (2011). Toward a clinical protocol for assessing rod, cone, and melanopsin contributions to the human pupil response. Investigative Ophthalmology and Visual Science, 52(9), 66246635.

Provencio, I., Cooper, H. M., \& Foster, R. G. (1998). Retinal projections in mice with inherited retinal degeneration: implications for circadian photoentrainment. Journal of Comparative Neurology, 395, 417-439.

Provencio, I., Rodriguez, I. R., Jiang, G., Hayes, W. P., Moreira, E. F., \& Rollag, M. D. (2000). A novel human opsin in the inner retina. Journal of Neuroscience, 20(2), 600-605.

Regan, B. C., Julliot, C., Simmen, B., Viénot, F., Charles-Dominique, P., \& Mollon, J. D. (2001). Fruits, foliage and the evolution of primate colour vision. Philosophical Transactions of the Royal Society of London B, Biological Sciences, 356(1407), 229-283.

Rosa, M. G. P., Soares, J. G. M., Fiorani, M., Jr., \& Gattass, R. (1993). Cortical afferents of visual area MT in the Cebus monkey: Possible homologies between New and Old World monkeys. Visual Neuroscience, 10, 827-855.

Rosa, M. G. P., Sousa, A. P. B., \& Gattass, R. (1988). Representation of the visual field in the second visual area in the Cebus monkey. Journal of Comparative Neurology, 275, 326-345.

Ruby, N. F., Brennan, T. J., Xie, X., Cao, V., Franken, P., Heller, H. C., \& O'Hara, B. F. (2002). Role of melanopsin in circadian responses to light. Science, 298(5601), 2211-2213.
Saito, A., Kawamura, S., Mikami, A., Ueno, Y., Hiramatsu, C., Koida, K., Fujita, K., Kuroshima, H., \& Hasegawa, T. (2005). Demonstration of genotype-phenotype correlation in polymorphic color vision of a non-callitrichine New World monkey, capuchin (Cebus apella). American Journal of Primatology, 67, 471-485.

Saito, C. A., da Silva Filho, M., Lee, B. B., Bowmaker, J. K., Kremers, J., \& Silveira, L. C. L. (2004). Alouatta trichromatic color vision: Single-unit recording from retinal ganglion cells and microspectrophotometry. Investigative Ophthalmology \& Visual Science, 45(5): E-Abstract 4276-B737.

Saito, C. A., Lee, B. B., Kremers, J., Silveira, L. C. L., da Silva Filho, M., \& Kilavik, B. E. (2001). Rod-cone interactions in the ganglion cell response: Studies using the diurnal capuchin-monkey and the nocturnal owl-monkey. Investigative Ophthalmology \& Visual Science, 42(4): S676.

Shimmin, L. C, Mai, P., \& Li, W. H. (1997). Sequences and evolution of human and squirrel monkey blue opsin genes. Journal of Molecular Evolution, 44, 378-382.

Shyue, S. K., Boissinot, S., Schneider, H., Sampaio, I., Schneider, M. P., Abee, C. R., ... Li, W. H. (1998). Molecular genetics of spectral tuning in New World monkey color vision. Journal of Molecular Evolution, 46, 697-702.

Shyue, S. K., Hewett-Emmett, D., Sperling, H. G., Hunt, D. M., Bowmaker, J. K., Mollon, J. D., \& Li, W. H. (1995). Adaptive evolution of color vision genes in higher primates. Science, 269, 1265-1267.

Silveira, L. C. L., Lee, B. B., Kremers, J., Silva-Filho, M., Saito, C. A., \& Kilavik, B. E. (2000). Receptor inputs and temporal dynamics of owl monkey ganglion cells. Investigative Ophthalmology \& Visual Science, 41(4): S937.

Silveira, L. C. L., Lee, B. B., Yamada, E. S., Kremers, J., \& Hunt, D. M. (1998). Post-receptoral mechanisms of colour vision in New World primates. Vision Research, 38, 3329-3337.

Silveira, L. C. L., Lee, B. B., Yamada, E. S., Kremers, J., Hunt, D. M., Martin, P. R., \& Gomes, F. L. (1999). Ganglion cells of a short-wavelength-sensitive cone pathway in New World monkeys: Morphology and physiology. Visual Neuroscience, 16, 333-343.

Silveira, L. C. L., Picanço-Diniz, C. W., Sampaio, L. F., \& OswaldoCruz, E. (1989). Retinal ganglion cell distribution in the Cebus monkey: A comparison with cortical magnification factors. Vision Research, 29, 1471-1483.

Silveira, L. C. L., Saito, C. A., Da Silva Filho, M., Bowmaker, J. K., Kremers, J., \& Lee, B. B. (2007). Physiological properties of photoreceptors and retinal ganglion cells from a trichromatic platyrrhine: The howler monkey, Alouatta sp. In L. C. L. Silveira, D. F. Ventura, \& B. B. Lee (Eds.), 19th Symposium of the International Colour Vision Society abstracts book (p. 69). Belém, Brazil: EDUFPA.

Silveira, L. C. L., Yamada, E. S., Perry, V. H., \& Picanço-Diniz, C. W. (1994). M and P retinal ganglion cells of diurnal and nocturnal New-World monkeys. Neuroreport, 5, 2077-2081.

Smallwood, P. M., Wang, Y. \& Nathans, J. (2002). Role of a locus control region in the mutually exclusive expression of human red and green cone pigment genes. Proceedings of the National Academy of Sciences of the United States of America, 99, 10081011.

Soares, J. G., Fiorani, M., Araujo, E. A., Zana, Y., Bonci, D. M. O., Neitz, M., ... Gattass, R. (2010). Cone photopigment variations in Cebus apella monkeys evidenced by electroretinogram measurements and genetic analysis. Vision Research, 50(1), 99106.

Stockman, A., \& Sharpe, L. T. (2000). The spectral sensitivities of the middle- and long-wavelength-sensitive cones derived from measurements in observers of known genotype. Vision Research, 40, 1711-1737.

Sumner, P., \& Mollon, J. D. (2000a). Catarrhine photopigments are optimized for detecting targets against a foliage background. Journal of Experimental Biology, 203, 1963-1986.

Sumner, P., \& Mollon, J. D. (2000b). Chromaticity as a signal of ripeness in fruits taken by primates. Journal of Experimental Biology, 203, 1987-2000.

Surridge, A. K., \& Mundy, N. I. (2002). Trans-specific evolution of opsin alleles and the maintenance of trichromatic colour vision in Callitrichine primates. Molecular Ecology, 11, 2157-2169. 
Surridge, A. K., Suárez, S. S., Buchanan-Smith, H. M., Smith, A. C., $\&$ Mundy, N. I. (2005). Color vision pigment frequencies in wild tamarins (Saguinus spp.). American Journal of Primatology, 67, 463-470.

Talebi, M. G., Pope, T. R., Vogel, E. R., Neitz, M., \& Dominy, N. J. (2006). Polymorphism of visual pigments in the muriqui (Primates, Atelidae). Molecular Ecology, 15, 551-558.

Tan, Y., Yoder, A. D., Yamashita, N., \& Li, W. H. (2005). Evidence from opsin genes rejects nocturnality in ancestral primates. Proceedings of the National Academy of Sciences of the United States of America, 102(41), 14712-14716.

Travis, D. S., Bowmaker, J. K., \& Mollon, J. D. (1988). Polymorphism of visual pigments in a callitrichid monkey. Vision Research, 28, 481-490.

Trezise, A. E., \& Collin, S. P. (2005). Opsins: Evolution in waiting. Current Biology, 15(19), R794-R796.

Wang, Y., Macke, J. P., Merbs, S. L., Zack, D. J., Klaunberg, B., Bennett, J., ... Nathans, J. (1992). A locus control region adjacent to the human red and green visual pigment genes. Neuron, 9(3), 429-440.

Williams, A. J., Hunt, D. M., Bowmaker, J. K., \& Mollon, J. D. (1992). The polymorphic photopigments of the marmoset: Spectral tuning and genetic basis. EMBO Journal, 11(6), 2039-2045.
Xue, T., Do, M. T., Riccio, A., Jiang, Z., Hsieh, J., Wang, H. C., ... Yau, K. W. (2011). Melanopsin signalling in mammalian iris and retina. Nature, 479(7371), 67-73.

Yamada, E .S., Silveira, L. C. L., \& Perry, V. H. (1996a). Morphology, dendritic field size, somal size, density and coverage of $\mathrm{M}$ and $\mathrm{P}$ retinal ganglion cells of dichromatic Cebus monkeys. Visual Neuroscience, 13, 1011-1029.

Yamada, E. S., Silveira, L. C. L., Gomes, F. L., \& Lee, B. B. (1996b) The retinal ganglion cell classes of New World primates. Brazilian Journal of Biology, 56, 381-396.

Yeh, T., Lee, B. B., Kremers, J., Cowing, J. A., Hunt, D. M., Martin, P. R., \& Troy, J. B. (1995). Visual responses in the lateral geniculate nucleus of dichromatic and trichromatic marmosets (Callithrix jacchus). Journal of Neuroscience, 15, 7892-7904.

Yokoyama, S. (2002). Molecular evolution of color vision in vertebrates. Gene, 300(1-2), 69-78.

Yokoyama, S., \& Radlwimmer, F. B. (1999). The molecular genetics of red and green color vision in mammals. Genetics, 153(2), 919932.

Zana, Y., Ventura, D. F., de Souza, J. M., \& DeVoe, R. D. (2001). Tetrachromatic input to turtle horizontal cells. Visual Neurosciences, 18(5), 759-765. 